
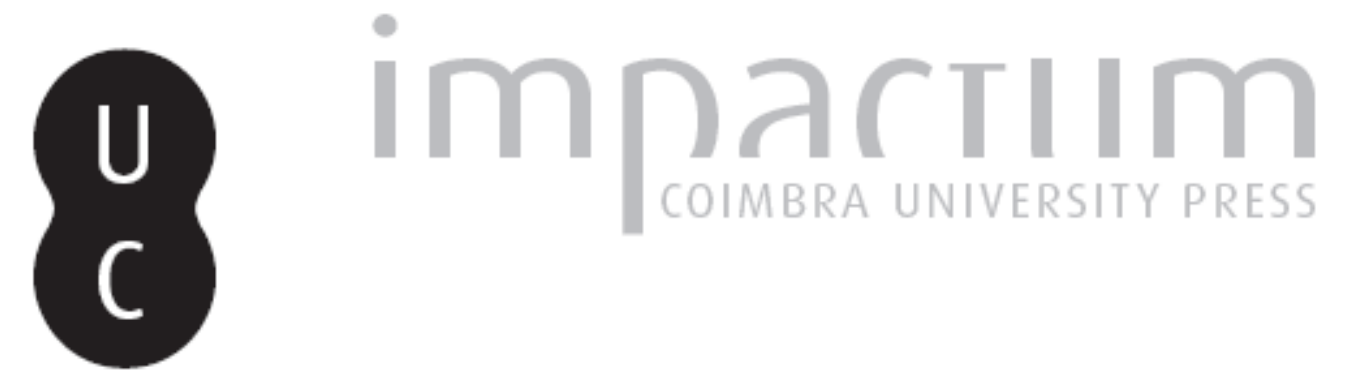

\title{
Fugindo dos "Grilhões do Cativeiro": os expostos pretos e pardos na Casa da Roda da Misericórdia de Lisboa (1780-1807)
}

\author{
Autor(es): $\quad$ Braga, Isabel M. R. Mendes Drumond \\ Publicado por: Centro de História da Sociedade e da Cultura \\ URL \\ persistente: \\ URI:http://hdl.handle.net/10316.2/39483 \\ DOI: \\ DOI:http://dx.doi.org/10.14195/1645-2259_11_9 \\ Accessed : $\quad$ 26-Apr-2023 12:57:14
}

A navegação consulta e descarregamento dos títulos inseridos nas Bibliotecas Digitais UC Digitalis, UC Pombalina e UC Impactum, pressupõem a aceitação plena e sem reservas dos Termos e Condições de Uso destas Bibliotecas Digitais, disponíveis em https://digitalis.uc.pt/pt-pt/termos.

Conforme exposto nos referidos Termos e Condições de Uso, o descarregamento de títulos de acesso restrito requer uma licença válida de autorização devendo o utilizador aceder ao(s) documento(s) a partir de um endereço de IP da instituição detentora da supramencionada licença.

Ao utilizador é apenas permitido o descarregamento para uso pessoal, pelo que o emprego do(s) título(s) descarregado(s) para outro fim, designadamente comercial, carece de autorização do respetivo autor ou editor da obra.

Na medida em que todas as obras da UC Digitalis se encontram protegidas pelo Código do Direito de Autor e Direitos Conexos e demais legislação aplicável, toda a cópia, parcial ou total, deste documento, nos casos em que é legalmente admitida, deverá conter ou fazer-se acompanhar por este aviso.

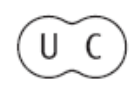




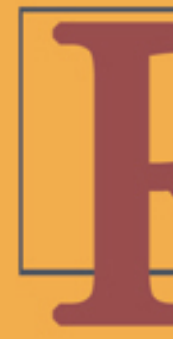

\section{evista de História} da Sociedade e da Cultura

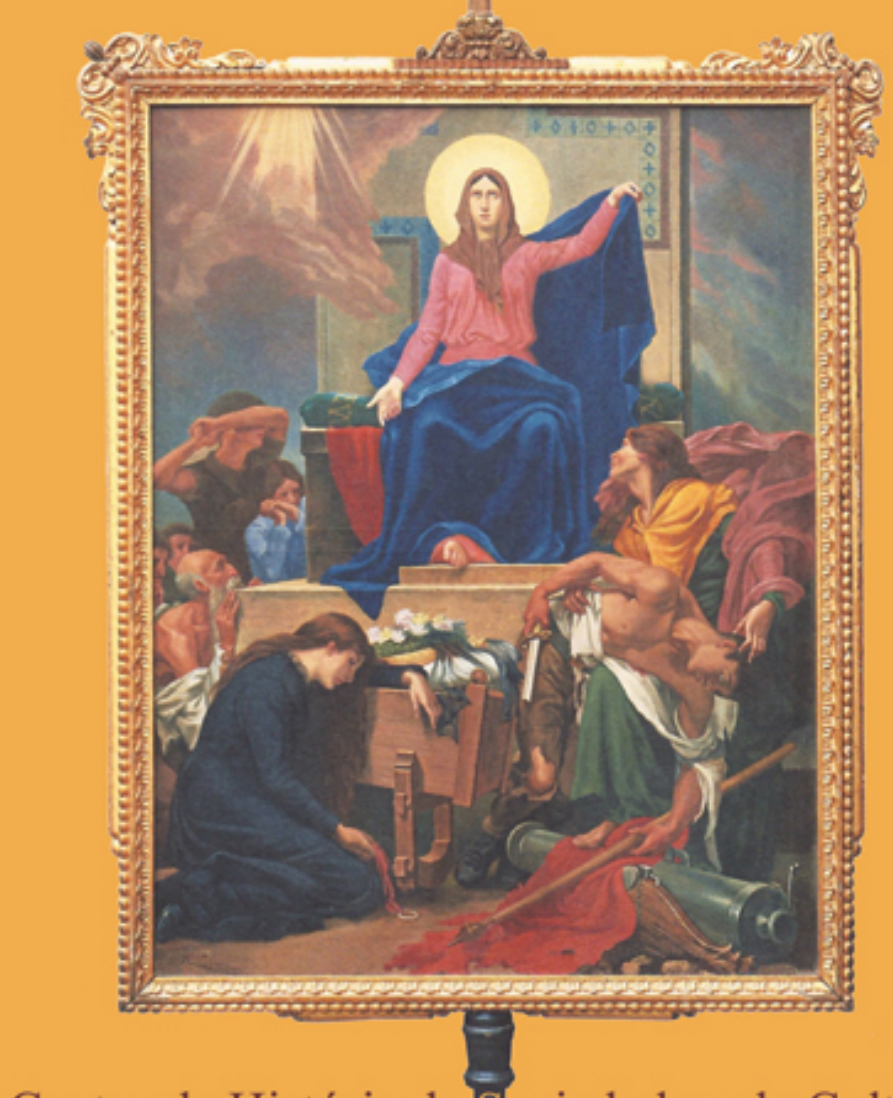

Centro de História da Sociedade e da Cultura Universidade de Coimbra 


\title{
Fugindo dos "Grilhões do Cativeiro": Os Expostos Pretos e Pardos na Casa da Roda da Misericórdia de Lisboa (1780-1807)
}

\author{
Isabel M. R. Mendes Drumond Braga \\ Professora Auxiliar com agregação e de nomeação definitiva da \\ Faculdade de Letras da Universidade de Lisboa \\ isabeldrumondbraga@hotmail.com \\ Texto recebido em/ Text submitted on: 01/10/2010 \\ Texto aprovado em/ Text approved on: 30/08/2011
}

\section{Resumo/Abstract:}

A partir dos livros de expostos dos negros registados na Misericórdia de Lisboa no período compreendido entre o início da escrita destas fontes e a saída da Corte para o Brasil, procuramos analisar as questões afectas ao abandono destas crianças a par das políticas desenvolvidas com vista a protegê-las desencadeadas pelas preocupações de José António de Castilho Furtado de Mendonça.

Drawing from the books of the negroes reports registered in Misericórdia of Lisbon between the beginning of writing these documents and the depart of the Court to Brazil, we study the issues regarding the abandonment of these children as well as the policies developed in order to protect them. The latter were aroused by the concerns of José António de Castilho Furtado de Mendonça.

Palavras chave/Keywords:

Expostos; Misericórdia de Lisboa; Negros; Portugal.

Foundling; Misericórdia of Lisbon; Negroes; Portugal. 
1. A 17 de Novembro de 1779, um parecer de José António de Castilho Furtado de Mendonça sobre a administração da Casa da Roda de Lisboa, que era feita pela Misericórdia, deu conta de informações preocupantes acerca dos expostos pretos e pardos que entravam naquela instituição: "Como nada há mais precioso que a liberdade, parece que nenhuma coisa deve primeiro importar-nos que os meios de conservá-la aqueles inocentes que a Providência incumbiu ao nosso cuidado, por cujo motivo julgo que o primeiro objecto que devo expor a Vossa Excelência é a infelicidade de alguns enjeitados pretos e pardos, que perdem a liberdade pelos mesmos meios de adquiri-la. Parece isto impossível, mas tem sucedido, e muitas vezes. Algumas daquelas pessoas que os vêm buscar à Casa da Roda para os criarem à custa da mesma, bárbara e furtivamente os vendem, e desta sorte fazem gemer toda a vida nos grilhões do cativeiro os mesmos inocentes, que o privilégio da Roda faz livres, e outros que já o eram. Bem se vê, que este ímpio e tirano roubo necessita do mais pronto e eficaz remédio; a mim me não ocorre outro mais próprio que o seguinte. Primeiramente, os assentos da entrada e saída dos ditos pretos e pardos, julgo se não devem fazer nos livros de entrada e saída dos expostos brancos, mas em outros separados, aonde se possam procurar, por exemplo, os 22 que entrarão no ano de 1778 , sem o trabalho e perda de tempo de se buscarem entre o total de 1484 expostos que entraram no mesmo ano. Também lhe pusera por extenso, à margem dos mesmos assentos, os nomes dos meninos, e em breve os das meninas, isto, ao fim de se gastar menos tempo quando se procura hum ou outro exposto. Os referidos pretos e pardos me parece se devem dar às amas-de-leite e seco, acrescentando às ordinárias condições que as primeiras pagarão à Casa da Rosa $15 \$ 000$, se acabado o tempo da criação os não vierem entregar, e as segundas $30 \$ 000$ caso de não cumprirem a mesma obrigação, pela qual devem também responder aos seus fiadores"1.

1 Portugaliae Monumenta Misericordiarum, coordenação científica de José Pedro Paiva, vol. 7 (Sob o signo da mudança: de D. José I a 1834), direcção científica de Maria Antónia Lopes e José Pedro Paiva, Lisboa, Universidade Católica Portuguesa, Centro de Estudos de História Religiosa, União das Misericórdias Portuguesas, 2008, pp. 552-553. 
Como se pode verificar, José António de Castilho Furtado de Mendonça ${ }^{2}$ identificou os problemas e recomendou medidas para os resolver. Estava em causa a perda de liberdade de negros e mulatos que, tendo nascido livres, acabavam por passar à condição de escravos, devido aos abusos daqueles que os deveriam proteger. Recordemos que, em 1761, D. José I tinha determinado que todos os negros que chegassem a Portugal após esta data seriam livres e, anos depois, em 1773, o mesmo monarca havia promulgado a chamada lei do ventre livre, pela qual se estabelecera que seria livre todo o que nascesse de mãe escrava ${ }^{3}$. Alterava-se, assim, a secular prática que determinava a condição do recém-nascido a partir do estatuto materno.

As preocupações do autor do parecer revelaram outros dados de interesse, nomeadamente a entrada de 1484 expostos no ano de 1778, dos quais 22 eram negros ou mulatos, representando apenas $1,5 \%$ do total das crianças abandonadas. Trata-se de uma percentagem muito baixa o que não impediu sensibilidade para o problema e apresentação de soluções, as quais foram tidas em conta pois, a partir de Junho de 1780, tiveram início os livros de entrada e baptismo de pretos e pardos e os livros das amas aos quais os expostos não brancos eram entregues ${ }^{4}$. É a partir desta documentação que iremos analisar, explicar e interpretar os dados que recolhemos afectos ao período compreendido entre Junho de 1780 e Dezembro de 1807, data a partir da qual a Corte se retirou para o Brasil 5 .

2 José António de Castilho Furtado de Mendonça terá nascido em 1725, uma vez que foi baptizado a 15 de Dezembro desse ano, na freguesia da Pena, em Lisboa. Recebeu o hábito da Ordem de Cristo a 10 de Abril de 1778, apesar de já contar mais de 50 anos, para o que teve autorização especial de D. Maria I. Cf. Lisboa, Arquivos Nacionais Torre do Tombo (ANTT), Habilitações da Ordem de Cristo, maço 51, n. ${ }^{\circ}$ 9. Casou-se com Madalena Xavier de Mendonça de quem teve um filho, Jerónimo José Xavier de Castilho, igualmente habilitado, a 18 de Abril de 1777. Cf. Lisboa, ANTT, Habilitações da Ordem de Cristo, maço 51, n. ${ }^{\circ} 17$.

3 Sobre a cronologia da escravatura, cf. Didier Lahon, "Da Escravidão à Liberdade", Os Negros em Portugal. Séculos XV-XIX, coordenação de Ana Maria Rodrigues, Lisboa, Comissão Nacional para as Comemorações dos Descobrimentos Portugueses, 1999, pp. 79-98.

4 Não obstante, alguns registos de negros e mulatos continuaram a ser feitos nos livros onde se registavam os expostos brancos.

5 Lisboa, Arquivo Histórico da Santa Casa da Misericórdia de Lisboa (AHSCML), $\mathrm{CE} / \mathrm{EE} / \mathrm{EB} / 03$, liv 1. 
2. A questão dos expostos começou a suscitar medidas legislativas durante o reinado de D. Manuel I. As câmaras assumiram os encargos com as crianças abandonadas por determinação régia ${ }^{6}$ embora alguns municípios tenham manifestado oposição e resistência alegando falta de verbas, tal foi, por exemplo, o caso do de Évora ${ }^{7}$. Em muitos casos, as Misericórdias assumiram a responsabilidade pelos expostos mas as despesas continuavam a estar a cargo dos concelhos. Para o efeito, foram celebrados contratos entre as duas instituições a nível local. As únicas preocupações e encargos das Misericórdias com as crianças desamparadas, à margem dos referidos contratos, eram pontuais e referiram-se àquelas cujos progenitores tinham morrido ou eram deficientes e não a enjeitados ${ }^{8}$.

6 Isabel dos Guimarães Sá, A Circulação de Crianças na Europa do Sul: o Caso dos Expostos do Porto no século XVIII, Lisboa, Fundação Calouste Gulbenkian, Junta Nacional de Investigação Científica e Tecnológica, 1995, pp. 89-92. Cf. também Idem, "The 'Casa da Roda do Porto': Reception and Restituion of Foundlings during the Eighteenth Century", Enfance Abandonnée et Société en Europe XIV - XX $X^{e}$ siècle, Roma, École Française de Rome, 1991, pp. 539-572.

7 Laurinda Abreu, “As Crianças Abandonadas no Contexto da Institucionalização das Práticas de Caridade e Assistência em Portugal, no século XVI", A Infância no Universo Assistencial da Península Ibérica (séculos XVI-XIX), organização de Maria Marta Lobo de Araújo e de Fátima Moura Ferreira, Braga, Instituto de Ciências Sociais da Universidade do Minho, 2008, pp. 31-49, maxime pp. 42-47.

${ }^{8}$ Isabel dos Guimarães Sá, A Circulação de Crianças [...], p. 105; Manuel de Oliveira Barreira, A Santa Casa da Misericórdia de Aveiro. Pobreza e Solidariedade (1600-1750), Coimbra, Dissertação de Mestrado em História Moderna apresentada à Faculdade de Letras da Universidade de Coimbra, 1995, pp. 142-143; Maria Dina dos Ramos Jardim, A Santa Casa da Misericórdia do Funchal no século XVIII, Funchal, Secretaria Regional do Turismo e Cultura, Centro de Estudos de História do Atlântico, 1996, pp. 133-134; Maria Marta Lobo de Araújo, Dar aos Pobres e Emprestar a Deus: as Misericórdias de Vila Viçosa e Ponte de Lima (séculos XVI-XVIII), [s.1.], Santa Casa da Misericórdia de Vila Viçosa e Santa Casa da Misericórdia de Ponte de Lima, 2000, pp. 271-272; Idem, "Pequenos e Pobres: a Assistência à Infância nas Misericórdias Portuguesas da Idade Moderna", A Infância no Universo Assistencial da Península Ibérica (séculos XVI-XIX), organização de Maria Marta Lobo de Araújo e de Fátima Moura Ferreira, Braga, Instituto de Ciências Sociais da Universidade do Minho, 2008, pp. 135-149; Martinho Vicente Rodrigues, A Santa Casa da Misericórdia de Santarém. Cinco séculos de História, Santarém, Santa Casa da Misericórdia de Santarém, 2004, pp. 274-278; Maria de Fátima Castro, A Misericórdia de Braga. Assistência Material e Espiritual (Das Origens a cerca de 1910), Braga, Santa Casa da Misericórdia de Braga, 2006, pp 269-27; António Magalhães, “Crianças Pobres e Doentes: a População Jovem como objecto de Práticas de Caridade na Santa Casa da Misericórdia de Viana da Foz do Lima (séculos XVI-XVIII)", A Infância no Universo Assistencial da Península Ibérica (séculos XVI-XIX), organização de Maria Marta Lobo de Araújo e de Fátima Moura Ferreira, Braga, Instituto de Ciências Sociais da Universidade do Minho, 2008, pp. 113-114. 
A Misericórdia de Lisboa começou a ocupar-se dos expostos a partir de 1635. Porém, a maior parte da documentação dos primeiros tempos desapareceu. De qualquer modo, a que resta é vasta e ainda aguarda investigadores. Tal como aconteceu um pouco por todo o Reino, e até mesmo no estrangeiro ${ }^{9}$, também na capital os expostos foram em número crescente em particular durante o século XVIII, época em que a maioria das Misericórdias atravessou dificuldades financeiras significativas, apesar de certas Casas conseguirem evidenciar alguma vitalidade ${ }^{10}$. O flagelo dos expostos e dos seus custos não eram alheios às preocupações dos contemporâneos Setecentistas e Oitocentistas, um pouco por todo o lado ${ }^{11}$. Por exemplo, no jornal manuscrito Folheto do Anno de 1753, fez-se saber que os expostos entrados pela roda e porta do Hospital Real de Todos os Santos perfizeram 1.038 - 512 rapazes e 526 raparigas - estando então

9 Para outros pontos da Europa, cf. François Lebrun, A Vida Conjugal no Antigo Regime, tradução de Carolina Queiroga Ramos, Lisboa, Edições Rolim, 1983, pp. 144-151; Jacques Gélis, L'Arbre et le Fruit. La Naissance dans l'Occident Moderne XVI-XIX siècles, Paris, Fayard, 1984, pp. 422-423; Volker Hunecke, "Les Enfants Trouvés: Contexte Européen et Cas Milanais (XVIII-XIX siècles)", Revue d'Histoire Moderne et Contemporaine, tomo 32, Paris, 1985, pp. 3-29; Volker Hunecke, "Intensità e Fluttuazioni degli Abbandoni dal XV al XIX secolo", Enfance Abandonnée et Société en Europe XIV - XX $X^{e}$ siècle, Roma, École Française de Rome, 1991, pp. 28-31; Linda A. Pollock, "Parent-Child Relations", Family Life in Early Modern Times 1500-1789, direcção de David I. Kertzer e Marzio Barbagli, New Haven, Londres, Yale University Press, 2001, pp. 215-217; Vicente Pérez Moreda, "La Infancia Abandonada en España, siglos XVI-XX", Asistencia y Caridad como Estrategias de Intervención Social: Iglesia, Estado y Comunidad (siglos XVI-XX), coordenação de Laurinda Abreu, Bilbau, Universidad del País Vasco/Euskal Herriko Unibersitatea, 2007, pp. 121-139 e a muito ampla bibliografia citada. Sobre as relações de vizinhança e a circulação de expostos de Reinos diferentes cf. Teodoro Afonso da Fonte, “A Assistência à Infância no Noroeste Peninsular. Instituições, Quadros Normativos, Estratégias Familiares e Circulação de Crianças entre o Minho e a Galiza nos séculos XVIII a XX", El Mar en los siglos Modernos, coordenação de Isidro Dubret e Hortensio Sobrado Correa, tomo 1, Santiago de Compostela, Xunta de Galicia, 2009, pp. 71-84.

${ }^{10}$ Maria Antónia Lopes, "As Misericórdias de D. José ao Final do século XX", Portugaliae Monumenta Misericordiarum, coordenação científica de José Pedro Paiva, vol. 1 (Fazer a História das Misericórdias), Lisboa, Centro de Estudos de História Religiosa, União das Misericórdias Portuguesas, 2002, pp. 67-69, passim, Idem, "De 1750 a 2000", Isabel dos Guimarães Sá, Maria Antónia Lopes, História Breve das Misericórdias Portuguesas 1498-2000, Coimbra, Imprensa da Universidade de Coimbra, 2008, p. 28.

${ }^{11}$ Sobre esta realidade para o século XIX, quer na literatura quer nos periódicos, cf. Caroline B. Brettell e Rui Feijó, "Foundling in Nineteenth-Century Northwestern Portugal: Public Welfare and Family Strategies", Enfance Abandonnée et Société en Europe XIV- XX siècle, Roma, École Française de Rome, 1991, pp. 273-300. 
vivas 2.797 crianças, após a morte de 652 durante o referido ano de 1753 . No mesmo espaço de tempo, o gasto com os expostos havia importado em 17.495.309 réis $^{12}$. Na realidade, os expostos, ao implicarem investimento económico, acabavam por interpelar a sociedade quer do ponto de vista dos custos quer dos valores morais e religiosos ${ }^{13}$.

A inexistência de trabalhos sobre o total dos expostos na Casa da Roda de Lisboa ${ }^{14}$ impede-nos de perceber se o abandono de negros e mulatos seguiu a mesma tendência verificada com a exposição dos brancos e de comparar a situação com a de outras Casas da Roda do Reino. De qualquer modo, a documentação em estudo permite apurar as entradas de expostos, a variação sazonal das mesmas, os horários em que se abandonaram as crianças, a taxa de masculinidade do grupo, o predomínio de pretos ou de pardos, os enxovais das crianças, os sinais dos expostos, a mortalidade infantil e o destino pontual de um ou outro exposto ${ }^{15}$.

As entradas dos abandonados costumam ser relacionadas com o aumento dos preços dos cereais, entendendo-se que tal levava à pauperização das famílias mais carenciadas e ao consequente abandono das crianças em opção ao infanticídio. Esta tese não explica, contudo, o facto de a maioria dos abandonos vitimar os recém-nascidos. De qualquer modo, sabe-se, por exemplo, que houve uma correlação entre os aumentos de preços de cereais e as entradas de expostos em espaços como Meda ${ }^{16}$, Setúba ${ }^{17}$, Porto $^{18}$ e Coimbra ${ }^{19}$.

${ }^{12}$ Évora, Biblioteca Pública de Évora (BPE), Folheto do Anno de 1753, n. ${ }^{\circ}$ 52, Lisboa, 29 de Dezembro de 1753. Cod. CIV/1-22d.

${ }^{13} \mathrm{Cf}$. as reflexões de Jean-Pierre Bardet, "La Société et 1'Abandon », Enfance Abandonnée et Société en Europe XIV-XXe siècle, Roma, École Française de Rome, 1991, pp. 3-26.

${ }^{14}$ Para os anos de 1786 a 1790, cf. Maria da Luz Ferreira Gouveia, O Hospital Real dos Expostos de Lisboa (1786-1790), 2 vols, Lisboa, Dissertação de Mestrado em História Regional e Local apresentada à Faculdade de Letras da Universidade de Lisboa, 2001.

${ }^{15}$ Para todos estes assuntos iremos basear-nos nos dados recolhidos in Lisboa, AHSCML, $\mathrm{CE} / \mathrm{EE} / \mathrm{EB} / 03$, liv 1 , fols $1-217 \mathrm{v}$

${ }^{16}$ Maria Antónia Lopes, "Os Expostos no Concelho da Meda em meados do século XIX”, Revista Portuguesa de História, tomo 21, Coimbra, 1985, p. 144.

${ }^{17}$ Laurinda Abreu, A Santa Casa da Misericórdia de Setúbal [...], p. 84.

${ }^{18}$ Isabel dos Guimarães Sá, A Circulação das Crianças [...], pp. 163, 173.

${ }^{19}$ Maria Antónia Lopes, Pobreza, Assistência e Controlo Social [...], vol. 1, pp. 286-288. 
Não fizemos tal avaliação para o caso em estudo. Observando o gráfico, podemos, contudo, verificar que os abandonos tiveram picos muito elevados nos anos de 1781 a 1785, tendo-se verificado uma tendência de decréscimo no início do século XIX, invertida em 1807, ano do início da primeira invasão francesa, o que poderá explicar este aumento.

Gráfico 1 - Entradas dos Expostos (1780-1807)

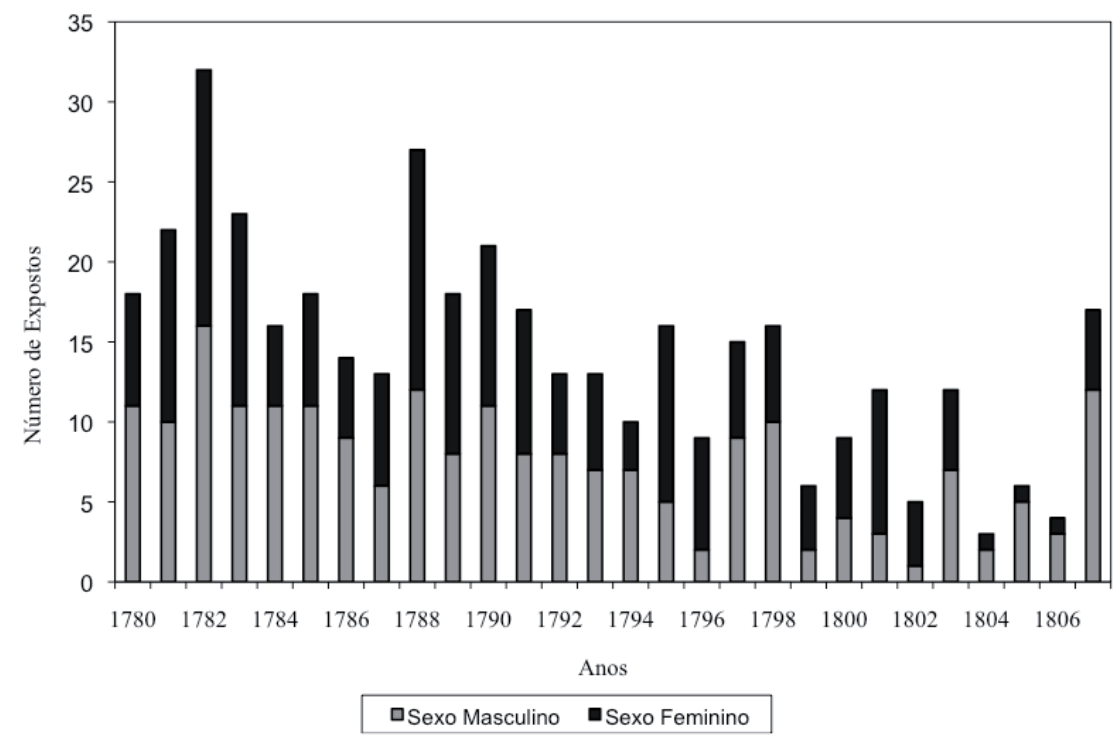

Se tivermos em conta as variações sazonais, podemos verificar que em Meda, Janeiro e Outubro foram os meses com mais expostos ${ }^{20}$, o mesmo acontecendo em Coimbra ${ }^{21}$. No Porto, predominaram os abandonos de Janeiro a Março, isto é, durante o Inverno ${ }^{22}$. Na Casa da Roda de Góis, a maior parte das entradas ocorreu em Março e em Maio ${ }^{23}$. Na sua congénere

${ }^{20}$ Maria Antónia Lopes, “Os Expostos no Concelho da Meda [...]”, p. 145.

${ }^{21}$ Maria Antónia Lopes, Assistência e Controlo Social. Coimbra (1750-1850), vol. 1, Viseu, Palimage, 2000, p. 290.

${ }^{22}$ Isabel dos Guimarães Sá, A Circulação de Crianças [...], p. 165.

${ }^{23}$ João Alves Simões, Os Expostos da Roda de Góis (1784-1841), Porto, Dissertação de Mestrado em História Contemporânea apresentada à Faculdade de Letras da Universidade do Porto, 1999, pp. 107-110. 
de Barcelos, foram os meses de Março, Abril e Maio os mais representativos ${ }^{24}$. Em Viana da Foz do Lima e em Ponte de Lima sobressaíram o final do Inverno e a Primavera ${ }^{25}$. Em Tomar predominaram as exposições em Abril, Maio e Março, ou seja, a maioria foi realizada no período compreendido entre o fim do Inverno e toda a Primavera ${ }^{26}$. Ou seja, não há consenso. Se o final do Inverno pode representar dificuldades alimentares acrescidas, a Primavera é uma época de trabalhos agrícolas durante a qual ainda não se procede às colheitas. Esta situação foi comum a outros espaços europeus ${ }^{27}$.

No caso em estudo, é possível verificar que a média mensal de abandonos é de 33,6 crianças. Os meses mais representativos foram os de Julho, com 45 entradas, seguindo-se Agosto e Abril com 42. Fevereiro e Setembro registaram 39 cada um, enquanto Novembro e Dezembro apresentaram valores próximos, com 37 exposições. Abaixo da média mensal cinco meses: Maio e Junho, com 31 casos, Janeiro e Outubro com 22 e, finalmente, Março, apenas com 17. Aparentemente, a época do ano teve pouca relação com o abandono dos negros e mulatos. Aliás, nesta questão há que ter em conta uma outra realidade: as concepções.

Das 405 entradas de expostos, 160, isto é, 39,5\%, foram realizadas em horário vespertino, 124, correspondentes a 30,6\%, de manhã e 111, ou seja, $27,4 \%$, de noite. Acrescem 10 casos, que representam 2,5\%, cujo momento não foi indicado. Esta situação não foi idêntica à que se verificou em outros espaços de abandono infantil em que a noite imperou contribuindo para acentuar não só o anonimato garantido pela roda mas também a discrição dos intervenientes ${ }^{28}$. A aumentar a percentagem de expostos entregues em

${ }^{24}$ Sebastião Matos, Os Expostos da Roda de Barcelos (1783-1835), Barcelos, Associação Cultural e Recreativa de Areias de Vilar, 1995, pp. 127-128.

${ }^{25}$ Teodoro Afonso da Fonte, No Limiar da Honra e da Pobreza. A Infância Desvalida e Abandonada no Alto Minho (1698-1924), Braga, Dissertação de Doutoramento apresentada ao Instituto de Ciências Sociais da Universidade do Minho, 2004, pp. 266-267.

${ }^{26}$ Graça de Abreu Arrimar Brás dos Santos, A Assistência da Santa Casa da Misericórdia de Tomar. Os Expostos 1799-1823, Tomar, Santa Casa da Misericórdia de Tomar, 2002, p. 168.

${ }^{27}$ Cf. Giovanna Da Molin, "Modalità dell'Abbandono e Caratteristiche degli Espositi a Napoli nel Seicento", Enfance Abandonnée et Société en Europe XIVE- XXe siècle, Roma, École Française de Rome, 1991, p. 480.

${ }^{28}$ Maria Antónia Lopes, "Os Expostos no Concelho da Meda [...]”, p. 133; Isabel dos Guimarães Sá, A Circulação de Crianças [...], pp. 130, 198, 202; João Alves Simões, Os Expostos da Roda de Góis [...], p. 93; Maria de Fátima Reis, Os Expostos em Santarém. 
Quadro 1 - Entradas de Expostos por Meses (1780-1807)

\begin{tabular}{|c|c|c|c|c|c|c|c|c|c|c|c|c|c|}
\hline & $\begin{array}{l}\stackrel{0}{\stackrel{\Xi}{\Xi}} \\
\stackrel{\Xi}{\leftrightarrows}\end{array}$ & 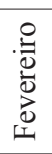 & 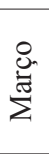 & 苞 & $\stackrel{\stackrel{0}{\pi}}{\Sigma}$ & 咅 & $\stackrel{ᄋ}{\equiv}$ & 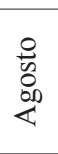 & $\begin{array}{l}\stackrel{\circ}{0} \\
\stackrel{0}{0} \\
\stackrel{0}{0} \\
\mathscr{n}\end{array}$ & 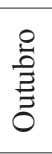 & 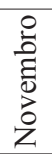 & 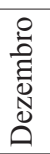 & 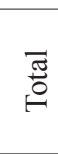 \\
\hline 1780 & 0 & 0 & 0 & 0 & 0 & 3 & 7 & 6 & 1 & 1 & 0 & 0 & 18 \\
\hline 1781 & 0 & 1 & 0 & 3 & 1 & 0 & 3 & 0 & 5 & 1 & 6 & 2 & 22 \\
\hline 1782 & 1 & 3 & 1 & 6 & 4 & 3 & 2 & 3 & 1 & 2 & 2 & 4 & 32 \\
\hline 1783 & 0 & 5 & 1 & 2 & 3 & 2 & 0 & 2 & 3 & 1 & 1 & 3 & 23 \\
\hline 1784 & 0 & 5 & 2 & 3 & 1 & 1 & 0 & 1 & 1 & 1 & 0 & 1 & 16 \\
\hline 1785 & 2 & 2 & 0 & 3 & 1 & 1 & 4 & 1 & 1 & 1 & 2 & 0 & 18 \\
\hline 1786 & 1 & 1 & 0 & 2 & 3 & 1 & 1 & 1 & 2 & 0 & 0 & 2 & 14 \\
\hline 1787 & 1 & 1 & 1 & 1 & 0 & 2 & 3 & 1 & 1 & 1 & 0 & 1 & 13 \\
\hline 1788 & 2 & 2 & 1 & 3 & 5 & 4 & 3 & 0 & 1 & 2 & 3 & 1 & 27 \\
\hline 1789 & 2 & 4 & 1 & 1 & 0 & 0 & 2 & 2 & 2 & 0 & 2 & 1 & 17 \\
\hline 1790 & 0 & 0 & 1 & 1 & 1 & 1 & 3 & 5 & 3 & 0 & 1 & 5 & 21 \\
\hline 1791 & 3 & 1 & 0 & 2 & 0 & 1 & 0 & 3 & 1 & 1 & 3 & 2 & 17 \\
\hline 1792 & 1 & 1 & 0 & 0 & 0 & 2 & 1 & 2 & 1 & 0 & 3 & 2 & 13 \\
\hline 1793 & 0 & 2 & 1 & 1 & 1 & 1 & 2 & 0 & 1 & 0 & 2 & 2 & 13 \\
\hline 1794 & 1 & 1 & 0 & 2 & 1 & 1 & 0 & 1 & 3 & 0 & 0 & 0 & 10 \\
\hline 1795 & 0 & 3 & 1 & 2 & 0 & 2 & 2 & 1 & 1 & 1 & 1 & 1 & 15 \\
\hline 1796 & 2 & 1 & 1 & 0 & 0 & 1 & 0 & 1 & 0 & 1 & 0 & 2 & 9 \\
\hline 1797 & 0 & 1 & 2 & 1 & 1 & 0 & 1 & 2 & 1 & 2 & 2 & 2 & 15 \\
\hline 1798 & 1 & 0 & 1 & 4 & 1 & 0 & 1 & 2 & 1 & 1 & 1 & 4 & 17 \\
\hline 1799 & 0 & 1 & 0 & 0 & 1 & 0 & 0 & 3 & 0 & 0 & 1 & 0 & 6 \\
\hline 1800 & 0 & 1 & 0 & 0 & 1 & 1 & 2 & 1 & 2 & 0 & 0 & 1 & 9 \\
\hline 1801 & 1 & 1 & 1 & 0 & 1 & 1 & 2 & 0 & 3 & 0 & 2 & 0 & 12 \\
\hline 1802 & 1 & 0 & 1 & 0 & 1 & 0 & 0 & 0 & 0 & 0 & 2 & 0 & 5 \\
\hline 1803 & 3 & 0 & 0 & 1 & 2 & 1 & 1 & 0 & 1 & 2 & 0 & 1 & 12 \\
\hline 1804 & 0 & 0 & 0 & 0 & 0 & 1 & 1 & 0 & 0 & 0 & 1 & 0 & 3 \\
\hline 1805 & 0 & 2 & 1 & 0 & 1 & 0 & 0 & 0 & 2 & 0 & 0 & 0 & 6 \\
\hline 1806 & 0 & 0 & 0 & 0 & 0 & 0 & 1 & 1 & 0 & 2 & 0 & 0 & 4 \\
\hline 1807 & 0 & 0 & 0 & 4 & 1 & 1 & 3 & 3 & 1 & 2 & 2 & 0 & 17 \\
\hline Total & 22 & 39 & 17 & 42 & 31 & 31 & 45 & 42 & 39 & 22 & 37 & 37 & 404 \\
\hline
\end{tabular}

Em 1795, há a juntar mais um exposto cujo registo só indica o ano. 
horário diurno contam-se as remessas de crianças provenientes de outras instituições, nomeadamente 22 do Hospital Real dos Enfermos, isto é, do Hospital Real de São José, um do Hospital Real de Todos os Santos, três da enfermaria de Santa Bárbara, dois da Casa da Roda de Belém e ainda cinco remetidos pelas câmaras de Alenquer, Cascais e Sintra. No caso dos particulares apenas ficou documentado o envio do negro Narciso José Romeiro, a 14 de Maio de 1781, pela marquesa de Castelo Melhor e condessa da Calheta, D. Mariana de Assis de Mascarenhas ${ }^{29}$.

Tal como foi comum em outras Casas da Roda, o abandono das crianças do sexo masculino foi superior ao das do sexo feminino ${ }^{30}$, embora sem se notar uma diferença acentuada. Ou seja, 211 rapazes face a 194 raparigas, isto é, $52 \%$ e $48 \%$ respectivamente, números que correspondem a uma taxa de masculinidade de 108,7 .

Se fizermos a destrinça entre negros e mulatos, verificamos que as percentagens de expostos do sexo masculino e do sexo feminino é muito próxima no caso dos primeiros, isto é, $17,8 \%$ de rapazes negros face a $17,3 \%$ de raparigas negras, enquanto no que se refere aos mulatos, as expostas

A Acção Social da Misericórdia (1691-1710), Lisboa, Cosmos, 2001, p. 89; Graça de Abreu Arrimar Brás dos Santos, A Assistência da Santa Casa da Misericórdia de Tomar [...], p. 163. Na Casa da Roda de Lisboa, entre 1786 e 1790, foi o horário matutino que predominou. Cf. Maria da Luz Ferreira Gouveia, O Hospital Real dos Expostos [...], vol. 1, p. 38. Em outros pontos da Europa, o abandono também foi mais significativo durante a noite. Cf., por exemplo, o que se viveu na Inclusa, uma casa de expostos de Madrid, in Claude Larquié, "La Mise en Nourice des Enfants Madrilènes au XVII siècle", Revue d'Histoire Moderne et Contemporaine, tomo 32, Paris, 1985, p. 130. Mas, também se verificaram excepções afins ao caso em estudo. Cf. Giovanna Da Molin, "Modalità dell'Abbandono [...]", pp. 457-502.

${ }^{29}$ Lisboa, AHSCML, CE/EE/EB/03, liv 1, fol. 12.

${ }^{30} \mathrm{O}$ mesmo aconteceu em outras localidades. Cf. Laurinda Abreu, A Santa Casa da Misericórdia de Setúbal de 1500 a 1755: Aspectos de Sociabilidade e Poder, Setúbal, Santa Casa da Misericórdia de Setúbal, 1990, p. 85; Isabel dos Guimarães Sá, A Circulação de Crianças [...], p. 165; Maria Antónia Lopes, Assistência e Controlo Social [...], p. 290; Graça de Abreu Arrimar Brás dos Santos, A Assistência da Santa Casa da Misericórdia de Tomar [...], p. 128; Maria da Luz Ferreira Gouveia, O Hospital Real dos Expostos [...], vol. 1, p. 40. Em Meda predominaram as raparigas abandonadas de 1838 a 1866, cf. Maria Antónia Lopes, “Os Expostos no Concelho da Meda [...]”, p. 145. Em Santarém, de 1691 a 1710, a situação foi semelhante. Cf. Maria de Fátima Reis, Os Expostos em Santarém [...], p. 98. Para o Alto Minho, cf. Teodoro Afonso da Fonte, No Limiar da Honra e da Pobreza [...], p. 265. Tal também se verificou em outros pontos da Europa. Contudo, houve excepções, como em Nápoles. Cf. Giovanna Da Molin, "Modalità dell’Abbandono [...]”, p. 471. 
representam 30,8\% enquanto os seus congéneres masculinos atingem a percentagem de $33,6 \%$. No universo em estudo, sabemos que predominaram os pardos com $64,4 \%$ face aos $35,1 \%$ de negros. Apenas em $0,5 \%$ dos casos desconhecemos se estamos perante pretos ou pardos.

Somente Isabel dos Guimarães Sá distinguiu números e percentagens de expostos brancos, pretos e pardos, concretamente os que foram entregues na Casa da Roda da Misericórdia do Porto. Apurou a autora que, entre 1690 e 1799, entraram na referida instituição 63.415 crianças, entre as quais se encontraram algumas não brancas. Uma análise a partir de uma amostra de 5.000 expostos permitiu verificar a presença de 100 mulatos e 42 negros, os quais representaram $2,5 \%$ dos abandonados ${ }^{31}$. Como verificámos no início, a percentagem apurada para a Casa da Roda da Misericórdia de Lisboa, para o ano de 1778 , foi de $1,5 \%$. Para a totalidade dos anos em estudo não temos como calcular essa percentagem pois desconhecemos os totais de expostos. Apenas sabemos que entre 1786 e 1790, deram entrada na Casa da Roda 6.575 crianças $^{32}, 93$ dos quais pretos e pardos, ou seja, a percentagem para estes anos foi de 1,4\%. No entanto, poderá ser ligeiramente mais elevada pois alguns registos continuaram a ser feitos nos livros dos expostos brancos.

A esmagadora maioria dos registos das crianças expostas, isto é, 92,3\%, não contem informações acerca da idade. Apenas 31 desses documentos, isto é, 7,7\%, a indicaram por vir referida em algum papel que acompanhava o abandonado ou por ser objecto de cálculo, o que era bastante raro. Nos registos em causa podemos verificar que 17 crianças tinham idades inferiores a um ano, idades essas compreendidas entre um e oito meses. Das restantes, sabemos que uma tinha um ano, outra três anos e uma terceira quatro anos, sete estavam pelo ano e meio de vida e quatro tinham dois anos. Todas as crianças cuja idade não foi indicada foram entregues a amas-de-leite o que permite conjecturar tratar-se de um grupo maioritariamente constituído por recém-nascidos ou por crianças ainda muito pequenas. A corroborar esta ideia está igualmente o facto de quase todos os expostos terem sido baptizados depois de entregues na Casa da Roda, com excepção

\footnotetext{
${ }^{31}$ Isabel dos Guimarães Sá, A Circulação de Crianças [...], pp. 198, 201.

${ }^{32}$ Maria da Luz Ferreira Gouveia, O Hospital Real dos Expostos de Lisboa [...], vol. 1,
} p. 33 . 
de seis que já haviam recebido o sacramento, tendo-se exibido documento do sacerdote que o comprovava. Este tipo de situações permitiu também verificar que a capacidade de atracção da Misericórdia de Lisboa chegava a Alenquer, Cascais, São Pedro de Almargem do Bispo e Sintra. Expostos de outras localidades não são de excluir, apenas não estão documentados.

Aparentemente, os expostos pretos e pardos deixados ou entregues na Casa da Roda eram crianças sem doenças identificáveis à primeira vista. Apenas em cinco casos se fizeram notar algumas situações fora do comum, a maioria deles representando algum tipo de deficiência. Se, em 1785, o negro Maximiliano, de cinco meses, foi qualificado de "aleijado" sem mais explicações ${ }^{33}$, em 1787, o pardo Pantaleão foi referido como alguém com feridas nos dedos ${ }^{34}$. Em 1789, o registo da parda Antónia fazia referência ao facto de a criança ter seis dedos na mão esquerda ${ }^{35}$. Em 1805, o negro Luís Machado, de ano e meio, foi descrito como doente, "leso das pernas"36, e, finalmente, em 1807, o pardo Francisco apresentou seis dedos em cada uma das mãos ${ }^{37}$. Ou seja, apenas a $1,2 \%$ dos expostos foram notadas questões de saúde, sendo as feridas nos dedos uma questão de pouca monta, ao contrário dos restantes problemas que configuravam deficiências físicas, muito embora não incapacitantes ${ }^{38}$.

${ }^{33}$ Lisboa, AHSCML, CE/EE/EB/03, liv 1, fol. 56.

${ }^{34}$ Lisboa, AHSCML, CE/EE/EB/03, liv 1, fol. 75.

${ }^{35}$ Lisboa, AHSCML, CE/EE/EB/03, liv 1, fol. 104.

${ }^{36}$ Lisboa, AHSCML, CE/EE/EB/03, liv 1, fol. 204v.

${ }^{37}$ Lisboa, AHSCML, CE/EE/EB/03, liv 1, fol. 211v.

${ }^{38}$ Faltam estudos de conjunto sobre a deficiência, numa perspectiva histórica. Constitui excepção Maria de Lurdes Rosa, "Imagem Física, Saúde Mental e Representação Familiar: a Exclusão dos Deficientes à Sucessão do Morgadio (Instituições, Legislação, Literatura Jurídica)", Arqueologia do Estado, 1. as Jornadas sobre Formas de Organização e Exercício dos Poderes na Europa do Sul. Séculos XIII-XVIII, Lisboa, História e Crítica, 1988, pp. 1059-1097. Alguns dados dispersos in Isabel M. R. Mendes Drumond Braga, "Violência Verbal e Violência Física numa Sociedade em Mudança: Portugal séculos XV-XVI", III Congresso Histórico de Guimarães D. Manuel e a sua Época, vol. 3 (População, Sociedade e Economia), Guimarães, Câmara Municipal, 2004, p. 500; Marco Liberato, "Trento, a Mulher e Controlo Social: o Recolhimento de São Marcos", Igreja, Caridade e Assistência na Península Ibérica (séculos XVI-XVIII), coordenação de Laurinda Abreu, Lisboa, Colibri, Évora, Centro Interdisciplinar de História, Cultura e Sociedades da Universidade de Évora, 2004, p. 282. Sobre deficiências físicas de outros expostos, cf. Maria da Luz Ferreira Gouveia, O Hospital Real dos Expostos [...], vol. 1, p. 35. Outras informações sobre expostos com doenças e deficiências in Giovanna Da Molin, "Modalità dell'Abbandono [...]”, pp. 489-490. 
A escolha do nome do exposto constituiu preocupação para $44 \%$ dos que procederam ao abandono. Isto é, 23 pessoas ao deixarem as crianças pediram que as mesmas fossem baptizadas com determinado nome e, em 155 casos, junto com os enjeitados foi deixado um escrito com indicações precisas acerca desta mesma questão. No que se refere aos restantes, quem escolheu e porquê constituem incógnitas, tanto mais que os nomes não são afins, a não ser pontualmente, aos do padrinho ou do sacerdote que administrou o sacramento.

Dos 405 expostos, 104, isto é, 57 raparigas e 47 rapazes, apresentaram nomes compostos, embora apenas 12 tivessem apelidos, o que permite pensar em filhos legítimos ou, pelo menos, em filhos cujos progenitores eram conhecidos ${ }^{39}$. Entre as 194 meninas, predominou o nome Maria com 50 ocorrências. Em 21 casos apenas Maria, nos restantes 29, Maria seguido de outro nome. A segunda escolha mais popular para o sexo feminino foi Ana com 12 casos, em oito das quais tratou-se de um nome composto. Entre os 194 rapazes, o nome que mais se destacou foi Manuel em 26 ocasiões, nove das quais em conjugação com um segundo nome. Seguiu-se José, com 18 casos, 12 dos quais igualmente em parceria com um segundo nome ${ }^{40}$. Registaram-se ainda nomes fora do comum, mesmo para a época, e que, entretanto caíram total ou parcialmente em desuso ${ }^{41}$, tais como Andreza, Aniceta, Bonifácia, Cipriana, Elisiária, Escolástica, Euleutéria, Febrónia, Libânia, Liberata e Torinda, entre as meninas e Euleutério, Escolástico, Estanislau, Ludgero, Mateus Procópio, Migino, Monório, Telesforo, Tibúrcio e Toríbio entre os rapazes.

No registo individual de entrada e baptismo de cada exposto apontava-se o vestuário e o enxoval - quando o havia - com que a criança dava entrada

\footnotetext{
${ }^{39}$ O mesmo aconteceu em Nápoles. Cf. Giovanna Da Molin, "Modalità dell'Abbandono [...]", pp. 468-470.

${ }^{40}$ Sobre a onomástica dos expostos, cf. Maria Antónia Lopes, "Os Expostos no Concelho da Meda [...]", pp. 138-139 (entre as mulheres predominaram os nomes Maria de Jesus, Maria Joaquina e Maria Antónia; entre os homens António Joaquim, António Maria e António Augusto); João Alves Simões, Os Expostos na Roda de Góis [...], pp. 94-95 (entre as crianças do sexo feminino: Maria, Joaquina e Rita, entre as do sexo masculino José Joaquim, Manuel, Joaquim, Francisco e António). Cf. também para o Alto Minho, Teodoro Afonso da Fonte, No Limiar da Honra e da Pobreza [...], pp. 306-310.

${ }^{41} \mathrm{O}$ mesmo aconteceu em Nápoles. Cf. Giovanna Da Molin, “Modalità dell’ Abbandono [...]", pp. 481-484.
} 
na Casa da Roda ${ }^{42}$. Tal como no caso dos brancos, a maioria dos negros e mulatos chegaram com poucas peças de roupa e, em alguns casos, velhas ou deterioradas. Algumas crianças apresentaram-se mesmo em precárias condições: uma foi entregue nua, 11 chegaram envoltas em pedaços de algodão, chita, estopa, linho, pano, paninho e peliceia ou até numa saca de lona e numa de serapilheira, enquanto 53 expostos envergaram roupas velhas, muito velhas, desbotadas, remendadas ou com muito uso. Poucas foram as crianças que além do vestuário também apresentavam peças de enxoval, tal como foram pouquíssimas, apenas três, as que chegaram com roupa em bom estado. Esta situação era afim à que se vivia em outros espaços europeus ${ }^{43}$.

$\mathrm{O}$ vestuário infanti1 ${ }^{44}$ era então sujeito a critérios bem diferentes dos da actualidade. Na realidade, para segurar a indumentária da criança recorria-se a ataduras diversas: atilhos, fitas, galões, ligas e ourelos dos mais variados tecidos e cores os quais seguravam cueiros, camisas e volvedouros. Registaram-se ainda, 10 alfinetes para o mesmo efeito. Das 405 crianças em estudo, a grande maioria foi entregue com um a quatro cueiros, sendo esta a peça mais citada, com mais de 600 menções. Seguiram-se as camisas, também em número variável, por norma uma ou duas, com mais de 300 referências. Bem menos significado numérico tiveram anáguas, aventais, calças, calções, coletes, manguitos, roupinhas, vestidos, vestias e saias.

${ }^{42} \mathrm{O}$ mesmo acontecia nas outras Casas da Roda, cf., por exemplo, António Luís Pinto da Costa, "A Roda Municipal dos Expostos de Murça", Brigantia, vol. 9, n. ${ }^{\circ}$ 1, Bragança, 1989, p. 79; Maria de Fátima Reis, Os Expostos em Santarém [...], p. 91; Maria Antónia Lopes, Pobreza, Assistência e Controlo Social [...], vol. 1, pp. 298-302; Graça Maria de Abreu Arrimar Brás dos Santos, A Assistência da Santa Casa da Misericórdia de Tomar [...], pp. 145-148. Sobre os gastos com os enxovais dos expostos, cf. Teodoro Afonso da Fonte, No Limiar da Honra e da Pobreza [...], pp. 293-296.

${ }^{43}$ Franca Doriguzzi, "Vestiti e Colori dei Bambini: il Caso degli Esposti", Enfance Abandonnée et Société en Europe XIV - XX' siècle, Roma, École Française de Rome, 1991, p. 516; Giovanna Da Molin, “Modalità dell'Abbandono [...]”, pp. 484-485.

${ }^{44}$ Sobre o nascimento do vestuário infantil, cf. Philippe Ariès, A Criança e a Vida Familiar no Antigo Regime, tradução de Miguel Serras Pereira e Ana Luísa Faria, Lisboa, Antropos, 1988, pp. 79-94. Sobre o Traje infantil em Portugal, cf. Maria José Palla, Do Essencial e do Supérfluo. Estudo Lexical do traje e Adornos em Gil Vicente, Lisboa, Estampa, 1992, pp. 59-61; Berta de Moura Sucena, Corpo, Moda e Luxo em Portugal no século XVIII, Lisboa, Dissertação de Mestrado em História Moderna apresentada à Faculdade de Letras da Universidade de Lisboa, 2007, pp. 53-145. 
Para cobrir a cabeça encontramos cueiros, pedaços de panos diversos, toalhas e peças mais apropriadas, tais como barretes, lenços de três e quatro pontas, mantilhas, toucas e ainda um chapéu. Refiram-se ainda 10 toalhas e mais de 80 volvedouros. Curiosamente nada foi indicado para proteger os pés.

A maioria das peças era confeccionada com panos baratos, nomeadamente de algodão, baeta, baetão, baetilha, bretanha, camelão, cavalim, chita, droga, droguete, durante, ganga, lã, linho, melania, paninho, pano-cru, pano rei, pelúcia, riscado, saragoça, serafina e serguilha, com claro predomínio para baeta, baetilha e baetão. Algumas peças eram debruadas e uma ou outra era guarnecida com renda. Embora residualmente, apareceram referências a tecidos com riscas e com motivos florais, nomeadamente ramos, raminhos e botões de rosa, a par de tecidos com salpicos ${ }^{45}$. Apenas de forma muito esporádica se nota algum requinte como, por exemplo, quando se recorre a camisas de cambraia, cassa ou linho com folhos e punhos de renda, a cintos e cueiros de cetim e de seda, a manguitos de veludo ou a barretes e toucas de cassa, cetim ou seda. Na realidade, estamos perante uma quase totalidade de peças confeccionadas com tecidos afins aos das que eram dadas como esmola aos pobres e que eram usadas pelos grupos com dificuldades em geral ${ }^{46}$.

As roupas dos menos favorecidos, confeccionadas com tecidos grosseiros e sem enfeites, eram de cores pálidas e sóbrias, o que não está desarticulado de um certo simbolismo ${ }^{47}$. No caso das roupas dos expostos a paleta

${ }^{45}$ Sobre as riscas e os motivos florais nos têxteis, cf. Michel Pastoureau, O Tecido do Diabo. Uma História das Riscas e dos Tecidos Listrados, tradução de Isabel Teresa Santos, Lisboa, Estampa, 1992; M.-A. Privat-Sauvigny, M.-H. Guelton, "Fleurons et Palmettes. Quelques Tissus à petits Motifs des années 1560-1630 destinés à l'Habillement", Paraître et se Vêtir au XVI siècle. Actes du XIII ${ }^{e}$ Colloque du Puy-en-Velay, estudos reunidos e apresentados por Marie Viallon, Saint-Etienne, Publications de l'Université de Saint-Etienne, 2006, pp. 223-240.

${ }^{46}$ Sobre o vestuário oferecido aos pobres por esmola, cf. Maria Marta Lobo de Araújo, Rituais de Caridade na Misericórdia de Ponte de Lima (séculos XVII-XIX), Ponte de Lima, Santa Casa da Misericórdia de Ponte de Lima, 2003, pp. 294-295; António Magalhães, "Crianças Pobres e Doentes [...]", pp. 120-122.

${ }^{47}$ Maria José Palla, Do Essencial e do Supérfluo [...], pp. 99-112; Maria Isabel Morán Cabanas, Traje, Gentileza e Poesia. Moda e Vestimenta no Cancioneiro Geral de Garcia de Resende, Lisboa, Estampa, 2001, pp. 542-560; Maria Marta Lobo de Araújo, Rituais de Caridade [...], pp. 304-306. O mesmo acontecia em outros espaços europeus. Cf. Marie-Joëlle Tupet, "Le Corps Vêtu: Le Vêtement de la Paysanne en Nouvelle Castille au tornant du XVI e siècle", Le Corps dans la Société Espagnole des XVI et XVII siècles, estudos reunidos e apresentados por Augustin Redondo, Paris, Publications de la Sorbonne, 1990, 
cromática é, contudo, muitíssimo variada. Se bem que as cores escuras estejam bem representadas: azul, azul ferrete, verde, roxo e preto, a par de pardo e cinzento, este referido residualmente; as cores claras, branco - também designado alvadio - cor-de-rosa, escarlate, carmesim, encarnado - aparecem as três designações - e amarelo também se fizeram sentir. Sem esquecer as combinações de cores nos debruns e nos tecidos com riscas e com motivos florais. Por outro lado, apareceram designações relativamente fora do comum como avinhado, melado, a par de cor de cana, de canela, de carne, de fogo, de ouro, de pérola e de pulga ${ }^{48}$.

Algumas crianças abandonadas eram acompanhadas pelos chamados sinais de expostos: bilhetes manuscritos, medalhas de santos, objectos diversos de ouro e prata, moedas, amuletos e contas, peças de roupa bordada, fitas, fragmentos de gravuras (metades) e gravuras inteiras. Constituíam meios de identificação da criança, no caso de mais tarde os pais a pretenderem recuperar, ao mesmo tempo que serviam para comunicar desejos ou dar informações, como por exemplo, qual o nome com que o exposto deveria ser baptizado e até para, pretensamente, proteger a criança ${ }^{49}$.

pp. 73-82; Pierre Civil, “Corps, Vêtement et Société. Le Coutume Aristocratique Espagnol dans la deuxième moitié du XVI siècle", Le Corps dans la Société Espagnole des XVI et $X V I I^{e}$ siècles, estudos reunidos e apresentados por Augustin Redondo, Paris, Publications de la Sorbonne, 1990, p. 313; Marie Viallon, "La Vêture du Pouvoir à Venise ou la Hiérarchie des Couleurs", Paraître et se Vêtir au XVI siècle. Actes du XIII Colloque du Puy-en-Velay, estudos reunidos e apresentados por Marie Viallon, Saint-Etienne, Publications de l'Université de Saint-Etienne, 2006, pp. 181-192.

${ }^{48}$ Compare-se com o que se sabe para a Casa da Roda de Coimbra. Cf. Maria Antónia Lopes, Pobreza, Assistência e Controlo Social [...], vol. 1, pp. 298-302. No Brasil, a situação era afim. Cf. Renato Venâncio, "Entre dois Impérios: a Santa Casa da Misericórdia e as 'Rodas dos Expostos' no Brasil”, As Misericórdias das duas Margens do Atlântico: Portugal e Brasil (séculos $X V$ - $X X$ ), organização de Maria Marta Lobo de Araújo, Cuiabá, Carlini e Caniato, 2009, p. 135. Em Turim, os expostos eram preferencialmente vestidos com peças brancas, a seguir, embora a grande distância, as peças encarnadas e as pretas. Cf. Franca Doriguzzi, "Vestiti e Colori dei Bambini [...]", pp. 523-531.

${ }^{49}$ Sobre os sinais dos Expostos, cf. Maria Antónia Lopes, "Os Expostos no Concelho da Meda [...]", pp. 135-137; Idem, Pobreza, Assistência e Controlo Social [...], vol. 1, pp. 293-296; Isabel dos Guimarães Sá, A Circulação de Crianças [...], pp. 204, 232-263; Francisco d'Orey Manoel, Maria Luísa Barbosa Colen, "Os expostos e Desamparados na Misericórdia de Lisboa”, Cidade Solidária. Revista da Santa Casa da Misericórdia de Lisboa, ano II, n. ${ }^{\circ}$ 2, Lisboa, 1999, pp. 38-49; João Alves Simões, Os Expostos da Roda de Góis [...], pp. 99-106; Maria de Fátima Reis, Os Expostos em Santarém [...], pp. 92-93; Graça Maria de Abreu Arrimar Brás dos Santos, A Assistência da Santa Casa da Misericórdia 
Mais de metade dos expostos pretos e pardos foram entregues acompanhados por sinais de expostos, nomeadamente por 155 bilhetes e por uma pequena colecção de objectos: contas, continhas e missangas de várias cores, galões e fitas diversas, algumas de seda, de diversas cores, e uma com um coral; dois crucifixos, três figas, uma das quais de marfim; três relicários, cinco evangelhos, cinco rosários, 14 breves, 33 medalhas variadas entre as quais verónicas e medidas; e ainda um cordão preto, um coração de madrepérola, uma lua de prata, uma meia-lua, uma cruz de pau, um dente de lobo e um livrinho.

Acolhidos os expostos, tratados pelas amas da Casa da Roda e seguidamente baptizados eram os mesmos entregues a amas-de-leite que se deveriam ocupar da criação, por norma, durante ano e meio. Seguiam-se as amas do seco, neste caso entre os 18 meses e os sete $\operatorname{anos}^{50}$. A partir de

de Tomar [...], p. 145; Teodoro Afonso da Fonte, No Limiar da Honra e da Pobreza [...], pp. 289-290 e 297-302. Vejam-se também dois catálogos dos sinais de expostos conservados na Misericórdia de Lisboa: Sinais de Expostos. Exposição Histórico Documental, Lisboa, Santa Casa da Misericórdia de Lisboa, 1987; Os Expostos da Roda da Santa Casa da Misericórdia de Lisboa, coordenação científica de Francisco d'Orey Manoel, [s.1.], Santa Casa da Misericórdia de Lisboa, 2001. Sobre estas realidades para outros espaços europeus, cf. Giovanna Da Molin, "Modalità dell'Abbandono [...]”, pp. 465-467; Anna Maria Maccelli, "Bambini Abbandonati a Prato nel XIX secolo: Il 'Segnale' come Testimonianza di un'Identità da Perdere o da Ritrovare”, Enfance Abandonnée et Société en Europe XIV - XX siècle, Roma, École Française de Rome, 1991, pp. 815-836; Isabelle Robin, Agnès Walch, "Les Billets trouvés sur les Enfants Abandonnés à Paris aux XVII et XVIII siècles", Enfance Abandonnée et Société en Europe XIV - XXe siècle, Roma, École Française de Rome, 1991, pp. 981-991; Jean-Pierre Bardet, Olivier Farnon, "Des Enfants sans Enfance. Sur les Abandonnés de l'Europe Moderne", Histoire de l'Enfance en Occident, vol. 2 (Du XVIII ${ }^{e}$ à nos Jours), direcção de Egle Becchi e Dominique Julia, Paris, Seuil, 1998, pp. 136-137. Para o Brasil, cf. Renato Venâncio, "Entre dois Impérios: a Santa Casa da Misericórdia [...]", pp. 125-131. Sobre os amuletos e os ritos de protecção infantil, cf. Maria Antónia Lopes, “Os Expostos no Concelho da Meda [...]”, p. 135; Jacques Gélis, L'Arbre et le Fruit [...], pp. 269-270.

${ }^{50}$ Sobre as amas, cf. Maria Antónia Lopes, "Os Expostos no Concelho da Meda [...]", pp. 146-151; Idem, Pobreza, Assistência e Controlo Social [...], vol. 1, pp. 222-272; Isabel dos Guimarães Sá, A Circulação de Crianças [...], pp. 277-305; Laurinda Abreu, A Santa Casa da Misericórdia de Setúbal [...], pp. 88-92; Maria de Fátima Reis, Os Expostos em Santarém [...], pp. 109-119; António Gomes Ferreira, Gerar, Criar, Educar. A Criança no Portugal do Antigo regime, Coimbra, Quarteto, 2000, pp. 178-206; Maria da Luz Ferreira Gouveia, O Hospital Real dos Expostos [...], vol. 1, pp. 92-183; Graça Maria de Abreu Arrimar Brás dos Santos, A Assistência da Santa Casa da Misericórdia de Tomar [...], pp. 203-219; Teodoro Afonso da Fonte, No Limiar da Honra e da Pobreza [...], pp. 311-348. 
então ${ }^{51}$ as crianças passavam a integrar as preocupações dos juízes dos órfãos que teriam de encontrar casas em que as mesmas fossem acolhidas e onde lhes fossem ensinados ofícios, estabelecendo-se, para o efeito, contratos de trabalho ${ }^{52}$.

As amas-de-leite dos pretos e pardos prestaram serviços a troco de 1.200 réis por mês. Esta quantia vigorou entre 16 de Junho de 1780 a 21 de Junho de 1787, data em que passou a 1.600 réis mensais. Por vezes, os contratos com as amas previram 15, 16 e até 17 meses de duração. Não estudámos as amas de forma aprofundada. Apenas fizemos algumas prospecções, as quais permitiram verificar que a maioria destas mulheres morava fora de Lisboa - em localidades como, e de entre outras, Alcobaça, Aljubarrota, Alverca, Barreiro, Cadaval, Carvalhal, Évora, Famões, Lourinhã, Minde, Óbidos, Ourém, Pombal, Porto de Mós, Rio Maior, Tomar, Vila Franca e Vimieiro - , era casada, havendo ainda a registar algumas viúvas. Entre as profissões dos cônjuges contaram-se alfaiates, artilheiros, fabricantes de sedas, fazendeiros, lavradores, marceneiros, sapateiros, serralheiros e trabalhadores. Ou seja, gente ligada à agricultura e aos ofícios ${ }^{53}$. Findo o tempo do contrato e continuando a dita criação, a ama faria termo de certidão em como a criança estava viva e bem-criada. Caso contrário, deveria entregar o exposto, ficando sujeita a multa no valor de 24.000 reis caso não cumprisse tal prerrogativa ${ }^{54}$. Quando as crianças faleciam em poder das amas estas tinham duas opções: dirigir-se à Casa da Roda de Lisboa onde entregavam o cadáver ou apresentar certidão de óbito do pároco da localidade em que o

${ }^{51}$ A partir dos sete anos era normal que a criança trabalhasse. Cf. Linda A. Pollock, "Parent-Child Relations", Family Life [...], p. 206-210.

${ }_{52}$ Sobre esta realidade para Évora, cidade em que, entre 1580 e 1837 foram expostas 16.515 crianças, das quais apenas 242 chegaram a auferir de contratos de trabalho, cf. Laurinda Abreu, "Un Destin Excepcionnel: Les Enfants Abandonnés au Travail (Évora, 1650-1837)", Annales de Démographie Historique, vol. 110, n. ${ }^{\circ}$ 2, Paris, 2005, pp. 165-183.

${ }^{53}$ Para a Casa da Roda de Lisboa, cf. Maria da Luz Ferreira Gouveia, O Hospital Real dos Expostos [...], vol. 1, pp. 97, 105-109. O mesmo acontecia em outros pontos da Europa, cf. Volker Hunecke, "Les Enfants Trouvés [...]", pp. 16-17; Claude Larquié, "La Mise en Nourice des Enfants [...]”, pp. 134-135; Francisco Chacón Jiménez, Rosa Elgarrista Domeque, Rafael Fresneda Collado, "Mercenarismo o Realidad? Análisis del Comportamento de las Amas en el Reino de Murcia (siglos XVII-XVIII)", Enfance Abandonnée et Société en Europe XIV $V^{-} X X^{e}$ siècle, Roma, École Française de Rome, 1991, pp. 405-437.

${ }^{54}$ Lisboa, AHSCML, CE/EA/CL/05/liv.1. 
exposto tinha perecido. Os dois casos estão documentados, predominando claramente o segundo.

Dos 405 expostos entregues na Casa da Roda, sabe-se que 230 passaram da ama-de-leite para a ama de seco ou para outrem. Isto é, uma criança ficou na Casa, apenas três foram entregues aos pais ou à mãe ${ }^{55}$ e 12 foram retiradas por ordem de fidalgas que os mandaram criar. Em apenas sete casos estas mulheres foram identificadas: a marquesa de Castelo Melhor, D. Mariana de Assis Mascarenhas, casada com o segundo marquês, D. António José de Vasconcelos e Sousa da Câmara Caminha Faro e Veiga, que em 1786 mandou criar a negra Mónica $^{56}$, a viscondessa de Vila Nova de Cerveira, D. Maria José de Assis, viúva, desde 1781, do $14 .^{\circ}$ visconde, D. Tomás Xavier de Lima Vasconcelos Brito Nogueira Teles da Silva, que, em 1787 e 1802, teve idêntico procedimento para com os negros Maximiana, Paulo e Perpétua ${ }^{57}$; a marquesa de Pombal, D. Maria Antónia de Meneses, mulher do segundo marquês D. Henrique José de Carvalho e Melo que, em 1805, se encarregou da criação do preto Benedito ${ }^{58}$; a marquesa de Abrantes, D. Maria Joana Xavier de Lima, mulher do 5. ${ }^{\circ}$ marquês, D. Pedro de Lencastre da Silveira Castelo Branco Sá e Meneses que, em 1806, pagou a criação da negra Joana Nepomuceno, mais tarde entregue aos pais $^{59}$ e três outras senhoras das quais só sabemos os nomes: D. Margarida Rosa que, em 1803, mandou criar uma menina parda ${ }^{60}$, D. Maria do Carmo Henriques de Melo que, na mesma data, teve procedimento afim face a uma menina negra ${ }^{61}$ e, mais tarde, em 1805 , em relação a outra menina ${ }^{62}$ e

${ }^{55}$ Sabe-se que a taxa de recuperação do exposto pela família biológica é baixa. Cf. Isabel dos Guimarães Sá, A Circulação de Crianças [...], pp. 171; Sebastião Matos, Os Expostos da Roda de Barcelos [...], pp. 163-170; Maria Antónia Lopes, Pobreza e Assistência [...], vol. 1, pp. 310-311; Graça Maria de Abreu Arrimar Brás dos Santos, A Assistência da Santa Casa da Misericórdia de Tomar [...], p. 197. O mesmo acontecia no estrangeiro. Cf. Volker Hunecke, "Intensità e Fluttuazioni [...]”, pp. 57-58; Carlo A. Corsini, “"Era Piovuto dal Cielo e la Terra L'Aveva Raccaltó': Il Destino del Trovatello”, Enfance Abandonnée et Société en Europe XIV-XXe siècle, Roma, École Française de Rome, 1991, pp. 105-106.

${ }^{56}$ Lisboa, AHSCML, CE/EE/EB/03, liv 1, fol. 69v.

${ }^{57}$ Lisboa, AHSCML, CE/EE/EB/03, liv 1, fols 71-71v e 195.

${ }^{58}$ Lisboa, AHSCML, CE/EA/NO/04/liv. 1, fol. 30v.

${ }^{59}$ Lisboa, AHSCML, CE/EA/NO/04/liv. 1, fol. 34.

${ }^{60}$ Lisboa, AHSCML, CE/EE/EB/03, liv. 1, fol. 200v.

${ }^{61}$ Lisboa, AHSCML, CE/EE/EB/03, liv. 1, fol. 197v.

${ }^{62}$ Lisboa, AHSCML, CE/EA/NO/04/liv. 1, fol. 29v. 
D. Teresa de Lencastre que, em 1804, se encarregou de pagar a alimentação da preta Clara $^{63}$.

Os restantes 214 expostos passaram ou foram logo entregues às amas do seco. Estas mulheres acabavam de criar e sustentar o exposto por tempo variável de três, quatro ou até cinco anos e meio, auferindo, para o efeito, de 500 réis cada mês, sem alteração ao longo dos tempos. Ao fim do contrato, a criança seria apresentada na Casa da Roda para "se por ao officio, a que a sua inclinação o destinar", caso a ama não o apresentasse teria que pagar soldadas ao arbítrio da Mesa da Misericórdia. Tal como no caso das amas-de-leite, as do seco eram maioritariamente casadas mas também havia viúvas e solteiras. Residiam em várias freguesias de Lisboa e em localidades diversas tais como, e de entre outras, Alcobaça, Alfeizerão, Cadaval, Óbidos, Pombal, Porto de Mós, Porto do Carro, Santa Maria da Azóia, Santarém, Vale de Salgueiro, Vale do Paraíso e Vimeiro. Entre os cônjuges destas amas contam-se: alfaiates, carpinteiros, fazendeiros, lavradores, oleiros, sapateiros, soldados, trabalhadores e homens que viviam das suas fazendas ${ }^{64}$. Isto é, quer as amas-de-leite quer as do seco parecem ter o mesmo tipo de vida.

Como no registo de entrada dos expostos se foram anotando dados, conhecemos partes dos destinos de muitas destas crianças. Isto é, os nomes das amas que tiveram, as datas em que foram entregues, a substituição de amas, quando tal aconteceu, e as datas em que os expostos faleceram. É visível que muitas amas - quer de leite quer do seco - acolheram mais do que um exposto. A mortalidade era elevada mas a procura de amas também. $\mathrm{Na}$ realidade, quase todas as amas, quer de leite quer do seco, cuidaram de mais do que uma criança, embora sem ser em simultâneo. Mesmo nos dois casos dos expostos gémeos foram os mesmos separados. Algumas amas continuaram as suas carreiras, com crianças diferentes, tratando primeiro dos mais pequenos, depois dos maiores de ano e meio. Dos sobreviventes apenas nos é dado saber que a parda Maria, entregue a 30 de Novembro de 1785 na Casa da Roda, foi emancipada a 22 de Março de $1815^{65}$ e que quatro raparigas ficaram a servir na referida instituição.

\footnotetext{
${ }^{63}$ Lisboa, AHSCML, CE/EA/NO/04/liv. 1, fol. 24v.

${ }^{64}$ Lisboa, AHSCML, CE/EA/CS/04/ liv. 1.

${ }^{65}$ Lisboa, AHSCML, CE/EE/EB/03, liv 1, fol. 63v. Alguns estudos sobre expostos dão conta de aspectos relevantes afectos à vida adulta. Cf. Maria Antónia Lopes, “Os Expostos
} 
Todos os estudos acerca de expostos dão conta das elevadas percentagens de mortes ${ }^{66}$. Os pretos e pardos não constituíram qualquer excepção, apresentando uma taxa de $76,7 \%$, mais alta do que aquela que se conhece para a totalidade dos expostos de Lisboa no período de 1787 a $1818^{67}$. Entre 1780 e 1807 entraram 405 negros e mulatos, dos quais faleceram, nesse mesmo período, 311 . De outras seis sabemos que os óbitos ocorreram dois em 1808, um em 1809 e os restantes três em 1838, 1858 e 1897, isto é, já na idade adulta. Apenas uma criança entrou morta, desconhecendo-se se a mesma já havia ou não sido baptizada ${ }^{68}$. Dos restantes, ignoramos as datas em que faleceram já adultos. Para o período em estudo, a média de mortes por ano foi de 11, o que esconde grandes assimetrias, como os anos de 1782 a 1785, os mais mortíferos, e os anos de 1804 a 1806, aqueles em que a morte fez menos vítimas, como se pode ver pelo gráfico.

no Concelho da Meda [...]", pp. 155-159; Idem, Pobreza, Assistência e Controlo Social [...], vol. 1, pp. 239-330; Maria da Luz Ferreira Gouveia, O Hospital Real dos Expostos de Lisboa (1786-1790) [...], pp. 80-90; Ana Maria Pires da Silva, O Casamento dos Expostos na Freguesia do Santíssimo Sacramento de Lisboa (1736-1887), Lisboa, Dissertação de Doutoramento em Antropologia Social apresentada ao Instituto de Ciências do Trabalho e da Empresa, 2002.

${ }^{66}$ Maria Antónia Lopes, "Os Expostos no Concelho da Meda [...]”, pp. 152-155; Idem, Pobreza, Assistência e Controlo Social [...], vol. 1, pp. 318-319; Laurinda Abreu, A Santa Casa da Misericórdia [...], pp. 85-87; Isabel dos Guimarães Sá, A Circulação das Crianças [...], pp. 205-210; Sebastião Matos, Os Expostos da Roda de Barcelos [...], pp. 170-174; João Alves Simões, Os Expostos da Roda de Góis [...], pp. 124-138; Graça Maria de Abreu Arrimar Brás dos Santos, A Assistência da Santa Casa [...], pp. 173-180; Maria da Luz Ferreira Gouveia, $O$ Hospital Real dos Expostos [...], pp. 54-63; Maria de Fátima Reis, Os Expostos em Santarém [...], pp. 119-120. No estrangeiro a situação era semelhante. Cf. Claude Larquié, "La Mise en Nourice [...]” pp. 136-138; Volker Hunecke, "Les Enfants Trouvés [...]", pp. 11-12; Alain Bideau, Guy Brunet, "La Mortalité des Enfants trouvés dans le Departement, de l'Ain aux XVIII ${ }^{\mathrm{e}}$ et XIX ${ }^{\mathrm{e}}$ siècles », Enfance Abandonnée et Société en Europe XIV $V^{-} X X^{e}$ siècle, Roma, École Française de Rome, 1991, pp. 219-248; Jean-Claude Sangoï, "La Mortalité Infantile en Europe Occidentale au XVIII" siècle", La Petite Enfance dans l'Europe Médiévale et Moderne, estudos reunidos por Robert Fossier, Toulouse, Presses Universitaires du Mirail, 1977, pp. 191-210; Colin Heywood, A History of Childhood. Children and Childhood in the West from Medieval to Modern Times, Cambridge, Oxford, Malden, Polity Press, 2001, pp. 59-60.

${ }^{67}$ João Pedro Ferro, A População Portuguesa no Final do Antigo Regime (1750-1815), Lisboa, Presença, 1985, p. 79.

${ }^{68}$ Sobre as crianças mortas sem baptismo, cf. Jacques Gélis, Les Enfants des Limbes. Mort-Nés et Parents dans l'Europe Chrétienne, [s.1.], Audibert, 2006. 
Gráfico 2 - Entradas e Mortes dos Expostos (1780-1807)

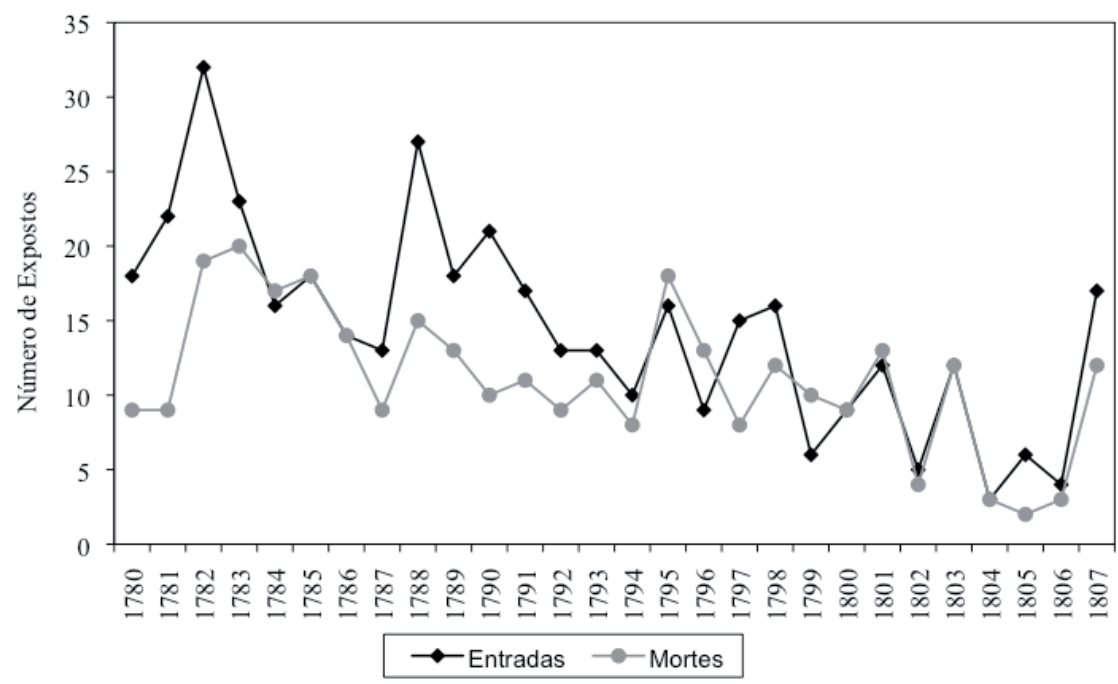

Partindo do princípio, não totalmente evidente, que as crianças cujas idades não foram indicadas eram recém-nascidas, podemos verificar que, dos 311 expostos falecidos, 105 , ou seja, 33,8\% morreram durante o primeiro mês de vida e que 267 , isto é, $85,8 \%$, não chegaram a completar um ano. Não obstante, às amas do seco foram entregues 214 crianças. Ultrapassaram os sete anos, 92 crianças, ou seja, $22,7 \%$ dos abandonados pretos e pardos que deram entrada na Casa da Roda de Lisboa.

A elevada mortalidade das crianças em geral ${ }^{69}$ e dos expostos em particular levou, desde o século XVII, a discussões académicas sobre a

${ }^{69}$ Muitos acidentes e problemas de saúde eram responsáveis pela morte de crianças e de adultos. Esta realidade acabou por ter repercussões na religiosidade popular, levando as populações a solicitar a intercessão dos santos e da Virgem para recuperar a saúde. Cf. Isabel M. R. Mendes, O Mosteiro de Guadalupe e Portugal (séculos XIV-XVIII). Contribuição para o Estudo da Religiosidade Peninsular, Lisboa, Junta Nacional de Investigação Científica e Tecnológica, 1994; Idem, "Milagres de Nossa Senhora de Montserrat num Códice da Biblioteca Nacional de Lisboa", Arquivos do Centro Cultural Calouste Gulbenkian, vol. 33, Lisboa-Paris, 1994, pp. 663-721; Pierre André Sigal, «Les Accidents de la Petite Enfance à la fin du Moyen Âge d'après les Récits de Miracles », La Petite Enfance dans l'Europe Médiévale et Moderne, estudos reunidos por Robert Fossier, Toulouse, Presses Universitaires du Mirail, 1997, pp. 59-76; Albrecht Burckardt, Les Clients des Saints: Maladie et Quête du Miracle á travers les Procès de Canonisation de la première moitiè du XVII siècle en France, Roma, École Française de Rome, 2004, pp. 207-229. 
questão. Neste domínio, os médicos tiveram papel de relevo ao proporem novos processos de aleitamento e diversas experiências nas quais os expostos acabaram por ser crianças cobaias. Contudo, a maior parte destes esforços não teve bons resultados ${ }^{70}$. Em Portugal, a questão também teve eco, em particular durante o século XIX. Pensemos nos textos de José Pinheiro de Freitas Soares e de Joaquim Pedro Fragoso de Siqueira, ambos publicados em 1812. O primeiro defendeu o uso de leite de vaca para alimentar as crianças em geral e os expostos em particular, alegando ser o mais parecido com o leite materno ${ }^{71}$. O segundo defendeu o recurso ao leite de cabra em detrimento do de ovelha ${ }^{72}$.

Factores como o estado de saúde e de nutrição da criança à chegada, os comportamentos das amas, o clima, as condições das casas em que viviam, as epidemias e as guerras podem ajudar a compreender as elevadas taxas de mortalidade. De qualquer modo, para os anos em causa, apenas o início da primeira invasão francesa poderá explicar a subida de mortes no ano de 1807, consentânea também com o aumento das entradas de expostos. Para os restantes anos de mortalidade elevada não temos explicações, apesar de serem conhecidos picos de mortalidade na cidade de Lisboa - os quais abrangeram a população em geral - nos anos de 1785-1788, 1792-1793 e no final da centúria, motivados por epidemias de febre tifóide, paratifóide, desinteria, tifo exantemático e febre palustre, bem como pelo aumento dos preços dos cereais ${ }^{73}$.

${ }^{70}$ Marie-France Morel “À Quoi servent les Enfants Trouvés? Les Médecins et le Problème de l'Abandon dans la France du XVIII siècle", Enfance Abandonnée et Société en Europe $X I V^{b}-X X^{e}$ siècle, Rome, École Française de Rome, 1991, pp. 837-858; Teodoro Afonso da Fonte, No Limiar da Honra e da Pobreza [...], pp. 175-181 e 348-352.

${ }^{71}$ José Pinheiro de Freitas Soares, Memoria sobre a preferência do Leite de Vaccas ao Leite de Cabras para o sustento das Crianças, principalmente nas grandes Casas de Expostos e sobre alguns outras Materias que dizem respeito a Criação delles, Lisboa, Tipografia da Academia, 1812.

${ }^{72}$ Joaquim Pedro Fragoso de Siqueira, "Memoria sobre a Creação e Vantagens do Gado Cabrum em Portugal", Memorias Economicas da Academia Real das Sciencias de Lisboa para o Adiantamento da Agricultura, das Artes e da Industria em Portugal e nas Conquistas, tomo 4, Lisboa, Tipografia da Academia, 1812.

${ }^{73}$ João Pedro Ferro, A População [...], pp. 76-77. 
3. Os escravos negros chegaram a Portugal em 1441, rapidamente começaram a organizar-se e a tentar proteger-se, nomeadamente através da instituição de irmandades sob a invocação de Nossa Senhora do Rosário dos Homens Pretos, cuja primeira foi fundada em Lisboa no ano de 1494. No Reino, dedicaram-se aos trabalhos domésticos, à agricultura, ao carregamento de navios e de carvão, à lavagem e escamação de peixe, à limpeza das ruas e desempenhavam ainda actividades em ferrarias. De qualquer modo, tiveram tendência para ir diminuindo, ao contrário do que aconteceu no Brasil onde o número de escravos negros aumentou significativamente ao longo dos séculos, ligado em especial aos engenhos de açúcar e à extracção de ouro e de gemas, em especial diamantes. Naquela colónia, a miscigenação deu origem a um importante e crescente número de mulatos os quais optaram por outras devoções tais como Nossa Senhora de Guadalupe, Nossa Senhora do Terço, Nossa Senhora do Amparo e, mais tarde, Nossa Senhora da Conceição, São Gonçalo Garcia (só canonizado em 1862, mas tido como santo no século XVIII e visto como o primeiro santo pardo da América) e Santo Elesbão e Santa Efigénia (africanos, o primeiro teria sido imperador da Etiópia e a segunda rainha da Núbia, segundo a tradição hagiográfica). Os pardos - que no Brasil faziam questão de não serem chamados mulatos, apresentando tal termo uma conotação negativa - e os negros escolheram devoções que comunicaram expectativas a respeito das hierarquias sociais e religiosas evidenciando diferenças ${ }^{74}$.

No Reino, os negros e os mulatos em estudo viveram numa época que assistiu ao início das campanhas abolicionistas na Europa ${ }^{75}$, em que o tráfico

${ }^{74}$ Sobre esta temática, cf. Larissa Viana, O Idioma da Mestiçagem. As Irmandades de Pardos na América Portuguesa, Campinas, Editora da Unicamp, 2007. Sobre crianças pardas no Brasil, expostas e não expostas, cf. Maria Beatriz Nizza da Silva, "O Problema dos Expostos na Capitania de São Paulo", Revista de História Económica e Social, vol. 5, Lisboa, 1980, pp. 95-104; Maria Luiza Marcilio, "Marginalidade, Pobreza e Abandono de Crianças no Brasil: séculos XVIII e XIX”, Revista de Ciências Históricas, vol. 11, Porto, 1996, pp. 163-173; Julita Scarano, "Crianças Esquecidas das Minas Gerais", História das Crianças no Brasil, organização de Mary Del Priore, São Paulo, Contexto, 2000, pp. 119-125; Uma História Social do Abandono das Crianças. De Portugal ao Brasil: séculos XVIII-XX, organização de Renato Pinto Venâncio, São Paulo, Alameda, Editora PUC Minas, 2010, na qual se reúnem diversos trabalhos relevantes sobre a matéria.

${ }^{75}$ António Carreira, Notas sobre o Tráfico Português de Escravos, 2. ${ }^{\text {a }}$ edição, Lisboa, Universidade Nova de Lisboa, Faculdade de Ciências Sociais e Humanas, 1983, p. 13, passim; 
de escravos em direcção à metrópole já estava proibido, desde $1761^{76}$, mas em que a alforria surgia ainda como uma conquista individual, pois era objecto de compra ou de dádiva ${ }^{77}$. Então, tal como no passado, o negro era ridicularizado em versos satíricos, folhetos de humor, almanaques e peças de teatro, onde o recurso à chamada "língua de preto" - com a adulteração do português na boca dos africanos - evidenciava a desigualdade e inferioridade do negro face ao branco ${ }^{78}$, apelando ao jocoso e provocando o riso. Na própria Corte de D. Maria I, a presença dos chamados "pretos da Rainha", um grupo de negros anões que compreendia um negro pigarço alardeava o exotismo em $\operatorname{voga}^{79}$. As marcas na toponímia - rua do Poço dos Negros, rua das Pretas, Pátio das Pretas, para só referir o caso de Lisboa - e a presença dos negros nos provérbios - citem-se apenas alguns: $O$ trabalho é bom para o preto; Preto velho não aprende línguas; Ganhá-lo como um preto e gastá-lo como um fidalgo; Meu preto não gosta de favas, favas no preto; Quem é preto de nação, nem a poder de sabão; Ao bom cavalo, espora - ao bom escravo, açoite $^{80}$ - são outros elementos que confirmam a presença e o status, ou a falta dele, dos negros na sociedade portuguesa setecentista. Finalmente, o sangue negro impedia o acesso a cargos e dignidade a todos os que eram negros ou mulatos ${ }^{81}$.

José Pedro Marques, Os Sons do Silêncio: o Portugal de Oitocentos e a Abolição do Tráfico de Escravos, Lisboa, Instituto de Ciências Sociais, 1999, p. 34, passim.

${ }^{76}$ Didier Lahon, "Da Escravidão à Liberdade [...]”, pp. 79-98.

77 Sobre as alforrias deste período, cf. Francisco Santana, "De Coisa a Pessoa - Análise de Alforrias Setecentistas", Boletim da Sociedade de Geografia de Lisboa, 117. série, n. ${ }^{\circ} 1-2$, Lisboa, 1999, pp. 181-204.

${ }^{78}$ José Ramos Tinhorão, Os Negros em Portugal. Uma Presença Silenciosa, 2. a edição, Lisboa, Caminho, 1997, pp. 187-331; Maria do Rosário Pimentel, Viagem ao Fundo das Consciências. A Escravatura na Época Moderna, Lisboa, Colibri, 1995, p. 57; Clara Rodrigues Dias Baltasar Lopes, Preto em Cordel (século XVIII). Jogo, Subversão, Preconceito, Lisboa, Dissertação de Mestrado em Literatura e Cultura Portuguesas - Época Moderna, apresentada à Faculdade de Ciências Sociais e Humanas da Universidade Nova de Lisboa, 1996; Isabel Castro Henriques, A Herança Africana em Portugal, Lisboa, CTT Correios de Portugal, 2008.

${ }^{79}$ Isabel M. R. Mendes Drumond Braga, “Os 'Pretos da Rainha'. Serviçais Exóticos na Corte de D. Maria I", IV Congresso Histórico de Guimarães. Do Absolutismo ao Liberalismo. Actas, vol. 2, [Guimarães], Câmara Municipal de Guimarães, 2009, pp. 37-67.

${ }^{80}$ Maria do Rosário Pimentel, Viagem ao Fundo [...], pp. 58-59.

${ }^{81}$ Isabel M. R. Mendes Drumond Braga, "A Mulatice como Impedimento de Acesso ao "Estado do Meio"”, O Espaço Atlântico de Antigo Regime: Poderes e Sociedades. Actas, Lisboa, Instituto Camões, 2008. Disponível em $c d$ rom e on line através do endereço 
Não obstante toda esta situação desfavorável, homens como José António de Castilho Furtado de Mendonça preocuparam-se em proteger dos "grilhões do cativeiro" crianças pretas e pardas cuja situação era de dupla pobreza e indigência, para não dizer miséria quase total. Os expostos brancos eram crianças muito pouco afortunadas, os expostos pretos e pardos juntavam a cor da pele ao abandono, configurando uma situação de dupla exclusão social. Neste grupo equacionar as questões da ilegitimidade versus pobreza ou a prática do abandono como meio de controlar o número de filhos parece ser bastante irrelevante. As estratégias pessoais de sobrevivência dos progenitores em época de crescente abandono infantil que, como se viu, era um problema estrutural e não conjuntural, foram paralelas ao incremento dos programas de protecção dos menores ligados aos ideais iluministas, um pouco por toda a Europa ${ }^{82}$. Os pais dos expostos negros e mulatos mais não fizeram do que aproveitar uma onda crescente em vigor por toda a Europa.

electrónico: http://www.instituto-camoes.pt/cvc/eaar/coloquio/comunicacoes/isabel_ drumond_braga.pdf.

${ }^{82}$ Hugh Cunningham, Children and Childhood in Western Society since 1500, Harlow, Longman, 1995, pp. 121-133; Buenaventura Delgado, Historia de la Infancia, Barcelona, Ariel, 2000, pp. 156-159. 